\title{
Preparation and Characterization of Epitaxially Grown Unsupported Yttria-Stabilized Zirconia (YSZ) Thin Films
}

\author{
Thomas Götsch ${ }^{\mathrm{a}}$, Lukas Mayr ${ }^{\mathrm{a}}$, Michael Stöger-Pollach ${ }^{\mathrm{b}}$, Bernhard Klötzer $^{\mathrm{a}}$, Simon Penner ${ }^{\mathrm{a}, *}$ \\ ${ }^{a}$ Institute of Physical Chemistry, Universität Innsbruck, A-6020 Innsbruck, Austria \\ ${ }^{b}$ University Service Center for Transmission Electron Microscopy (USTEM), Vienna University of Technology, A-1040 \\ Vienna, Austria
}

\begin{abstract}
Epitaxially grown, chemically homogeneous yttria-stabilized zirconia thin films ("YSZ", 8 mol\% $\mathrm{Y}_{2} \mathrm{O}_{3}$ ) are prepared by direct-current sputtering onto a single-crystalline $\mathrm{NaCl}(001)$ template at substrate temperatures $\geq 493 \mathrm{~K}$, resulting in unsupported YSZ films after floating off $\mathrm{NaCl}$ in water.

A combined methodological approach by dedicated (surface science) analytical characterization tools (transmission electron microscopy and diffraction, atomic force microscopy, angle-resolved X-ray photoelectron spectroscopy) reveals that the film grows mainly in a [001] zone axis and no Y-enrichment in surface or bulk regions takes place. In fact, the Y-content of the sputter target is preserved in the thin films. Analysis of the plasmon region in EEL spectra indicates a defective nature of the as-deposited films, which can be suppressed by post-deposition oxidation at $1073 \mathrm{~K}$. This, however, induces considerable sintering, as deduced from surface morphology measurements by AFM.

In due course, the so-prepared unsupported YSZ films might act as well-defined model systems also for technological applications.
\end{abstract}

Keywords: thin films, surface morphology, YSZ, TEM

\section{Introduction}

Some of the defining characteristics that make yttria-stabilized zirconia (YSZ) ideal for applications such as chemical sensors or intermediate-temperature solid oxide fuel cells (IT-SOFCs) are its high ionic conductivity,[1] as well as its thermal stability and chemical inertness. In fact, YSZ is the most utilized electrolyte in SOFCs.[2]

Hence, there have been numerous reports dealing with the analysis of YSZ thin films created by various deposition techniques, particularly with regard to the application as electrolyte in SOFCs. The variety in

*Corresponding author: Simon Penner, Innrain 80/82, A-6020 Innsbruck, Austria; Email, simon.penner@uibk.ac.at; Phone, $+4351250758003$ 
deposition methods has been vast: some groups have used sputtering, ranging from direct current, $[3,4]$ radiofrequency $[5-7]$ or magnetron sputtering $[4,8,9]$ to more complex variants such as reactive sputtering, $[4,8-11]$ where the targets are metals and the sputtered particles react with oxygen, or pulsed sputtering versions. [8] Others utilized different physical vapour deposition (PVD) techniques like pulsed laser deposition (PLD), [1117] spray pyrolysis[17-20], electrospray[21, 22] and electron-beam evaporation.[23] Chemical vapour deposition (CVD) methods have also been applied, where aerosol-assisted CVD has been prominent.[17, 24, 25] Additionally, there have been reports of thin films being synthesized using sol-gel pathways[26, 27] and atomic layer deposition (ALD).[11, 28]

Since these films were generally analyzed with their possible use as electrolyte layers in mind, their thicknesses are usually between several hundred nanometers $[5,8,15,17-21,24,25,29-32]$ and the micrometer range. [3, 6, 7, 10, 14, 23, 27, 33, 34] The characterization of the thin films has commonly comprised structural analyses of the morphologies (both surfacial and cross-sectional, yielding such data as surface roughness values, microstructure and porosity), grain size, or degree of crystallinity and orientation of the deposited material. In addition to those properties, electrical characteristics have been investigated extensively as well. Even though it has also been shown that YSZ can be used as a supporting oxide for the anodic catalyst in SOFCs, [35] there is a lack of research regarding the potential use as catalytical material. Since for such analyses, any additional contribution towards catalytical turnover is to be avoided, most of the published setups, where the YSZ thin film is never removed from the substrate, are not employable - especially since some of the substrates used are adequate catalysts themselves (e.g., the NiO/YSZ anodes[10, 21, 27, 34, 36]). Additionally, the thickness required for electrolytes provides an additional drawback as it prohibits analysis using transmission electron microscopy (TEM) due to not being electron transparent. If thin enough, the films can easily be investigated by means of TEM in order to establish structure-activity relationships and to fully characterize the sample (structure, distribution of yttrium, presence of different phases etc.) before any activities are measured.

To present such films suitable for electron microscopy and technological applications, one has to overcome the limitations inherent to previously discussed thin films. In this respect, we prepared unsupported thin films of YSZ of much lower thickness than usually reported in the literature (in the range of $25 \mathrm{~nm}$, making them electron-transparent) by utilizing a direct-current sputter gun,[37] equipped with a YSZ target, via of our dedicated model catalyst approach. As substrates for the epitaxial growth of the oxide, freshly-cleaved $\mathrm{NaCl}(001)$ single crystals were used, from which the thin films could be floated off before being placed on gold TEM grids to yield free-standing thin films. 


\section{Material and Methods}

\subsection{Deposition of the Thin Films}

The thin films have been prepared by direct-current sputtering using a modular high-vacuum apparatus, enabling a base pressure of less than $1 \times 10^{-4} \mathrm{~Pa}$. For the deposition procedure, a self-made sputter gun, [37] equipped with a YSZ pellet ( $8 \mathrm{~mol} \% \mathrm{Y}_{2} \mathrm{O}_{3}$, Aldrich Zirconium(IV) oxide yttria stabilized) as target, was utilized. The deposition was conducted in around $5 \times 10^{-3} \mathrm{~Pa}$ of Argon, the atoms of which were ionized using electrons emitted from a tungsten filament looped around a tantalum cage with a bias of around $400 \mathrm{~V}$ to extract the electrons. The argon ions were then accelerated toward the target with a bias of $-2000 \mathrm{~V}$. Freshly-cleaved $\mathrm{NaCl}(001)$ single crystals were used as substrates, which could be heated up to $623 \mathrm{~K}$, eventually allowing for epitaxial growth at various deposition temperatures (higher substrate temperatures are excluded due to the increasing vapor pressure of $\mathrm{NaCl}$ ). The target-to-substrate-distance was approximately $4 \mathrm{~cm}$ and the sputtering, which was performed using a horizontal alignment of substrate holder and sputter gun, was run for 24 hours at a sputter current of around $120 \mu \mathrm{A}$. This resulted in mean nominal film thicknesses of around $40 \mathrm{~nm}$.

The thin films were then floated-off from the $\mathrm{NaCl}$ substrates and collected on a transmission electron microscopy gold grid, yielding free-standing, electron-transparent thin films. For some of the samples, postannealing treatments were performed, where the samples (placed on the gold grids) were placed inside a muffle furnace (in air) and heated to temperatures up to $1073 \mathrm{~K}$ to study their crystallization behaviour in dependence of the deposition temperature and their general thermal and structural stability.

\subsection{Characterization of the Thin Films}

The crystallinity, chemical homogeneity and structure of the samples were investigated using a FEI Tecnai F20 STWIN (high-resolution) analytical (scanning) transmission electron microscope by means of selected area electron diffraction (SAED), electron energy-loss spectrometry (EELS) and energy-dispersive x-ray spectrometry (EDXS).

For surface analysis using (angle-resolved) X-ray photoelectron spectroscopy (XPS), a dedicated UHV system (base pressure: low $10^{-10}$ mbar range) was used. Details are discussed elsewhere.[38] Characterization of the films was performed using a Thermo Electron Alpha 110 XPS/Auger/LEIS spectrometer equipped with a standard double $\mathrm{Mg} / \mathrm{Al}$ anode X-ray gun (XR 50, SPECS). To perform the XPS analysis, the films have been simultaneously grown on a conductive $\mathrm{Cu}$ foil, which was subsequently transferred to the UHV chamber via a load-lock system.

Additionally, the surface topography was studied using atomic force microscopy (AFM), utilizing a Veeco Digital Instruments Dimension 3100 instrument in tapping mode in order to investigate the substrate temperature-dependence of the morphology as well as the surface roughness. The images were recorded 
using Veeco RTESPW silicon cantilevers with force constants from $20 \mathrm{~N} \mathrm{~m}^{-1}$ to $80 \mathrm{~N} \mathrm{~m}^{-1}$ and resonance frequencies of $256 \mathrm{kHz}$ to $317 \mathrm{kHz}$.

\section{Results and Discussion}

\subsection{Purity and Homogeneity}

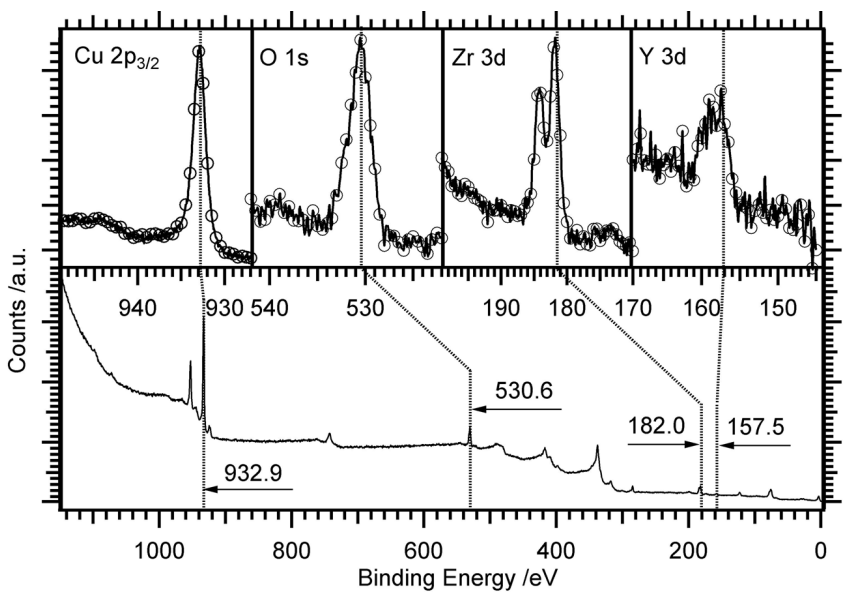

Figure 1: XPS overview spectrum of the as-deposited YSZ film as a function of binding energy (main panel). The insets show details of the $\mathrm{Cu} 2 \mathrm{p}_{3 / 2}, \mathrm{O} 1 \mathrm{~s}, \mathrm{Zr} 3 \mathrm{~d}$ and $\mathrm{Y} 3 \mathrm{~d}$ regions. Note that the $\mathrm{Cu}$ signal is due to the Cu foil used as conducting substrate for XPS.

The overview XP spectrum shown in Figure 1 (lower panel) reveals that, apart from the expected peaks due to the sputtered film ( $\mathrm{Zr}, \mathrm{Y}$ and $\mathrm{O}$ ) and the underlying $\mathrm{Cu}$-foil substrate (used to transfer the film to the UHV chamber), all other impurities are below the detection limit. The upper panel, in turn, highlights a set of important peak regions, namely $\mathrm{Cu} 2 \mathrm{p}_{3 / 2}, \mathrm{O} 1 \mathrm{~s}, \mathrm{Zr} 3 \mathrm{~d}$ and $\mathrm{Y} 3 \mathrm{~d}$. The ratio of yttrium $\left(\mathrm{Y} 3 \mathrm{~d}_{5 / 2}\right.$ at $157.5 \mathrm{eV} \mathrm{BE}$ ) to zirconium ( $\mathrm{Zr} 3 \mathrm{~d}$ at $182.0 \mathrm{eV} \mathrm{BE}$ ) to oxygen (O 1s at $530.6 \mathrm{eV} \mathrm{BE}$ ) can be determined from XPS as $7: 31: 62$, considering that $\mathrm{O} 1$ s also includes contributions from oxidized $\mathrm{Cu}$ species. Hence, the Zr-to-Y ratio is basically that of the YSZ powder used as the sputtering target. Note that the peak shifts observed both for Zr 3d and Y 3d are those typically found for fully oxidized Zr and Y species, indicating that substantial amounts of substoichiometric and/or metallic entities are basically absent.[39]

For determination of the chemical homogeneity of the surface-near regions - in close correlation to the HAADF-STEM results sampling the three-dimensional bulk - angle-resolved XPS experiments have been additionally carried out. In these experiments, varying the incidence angle from $0^{\circ}$ (most bulk sensitive) to $60^{\circ}$ (most surface-sensitive) allows precise determination of the $\mathrm{O}, \mathrm{Y}$ and $\mathrm{Zr}$ content perpendicular to the surface. These experiments are shown in Figure 2. The left panels highlight the respective XPS peaks taken at various analysis angles $\left(0^{\circ}, 18^{\circ}, 38^{\circ}\right.$ and $\left.58^{\circ}\right)$, subsequently used to determine the atomic percentage of those elements within the film (right panel). Two features are immediately obvious: firstly, no pronounced 

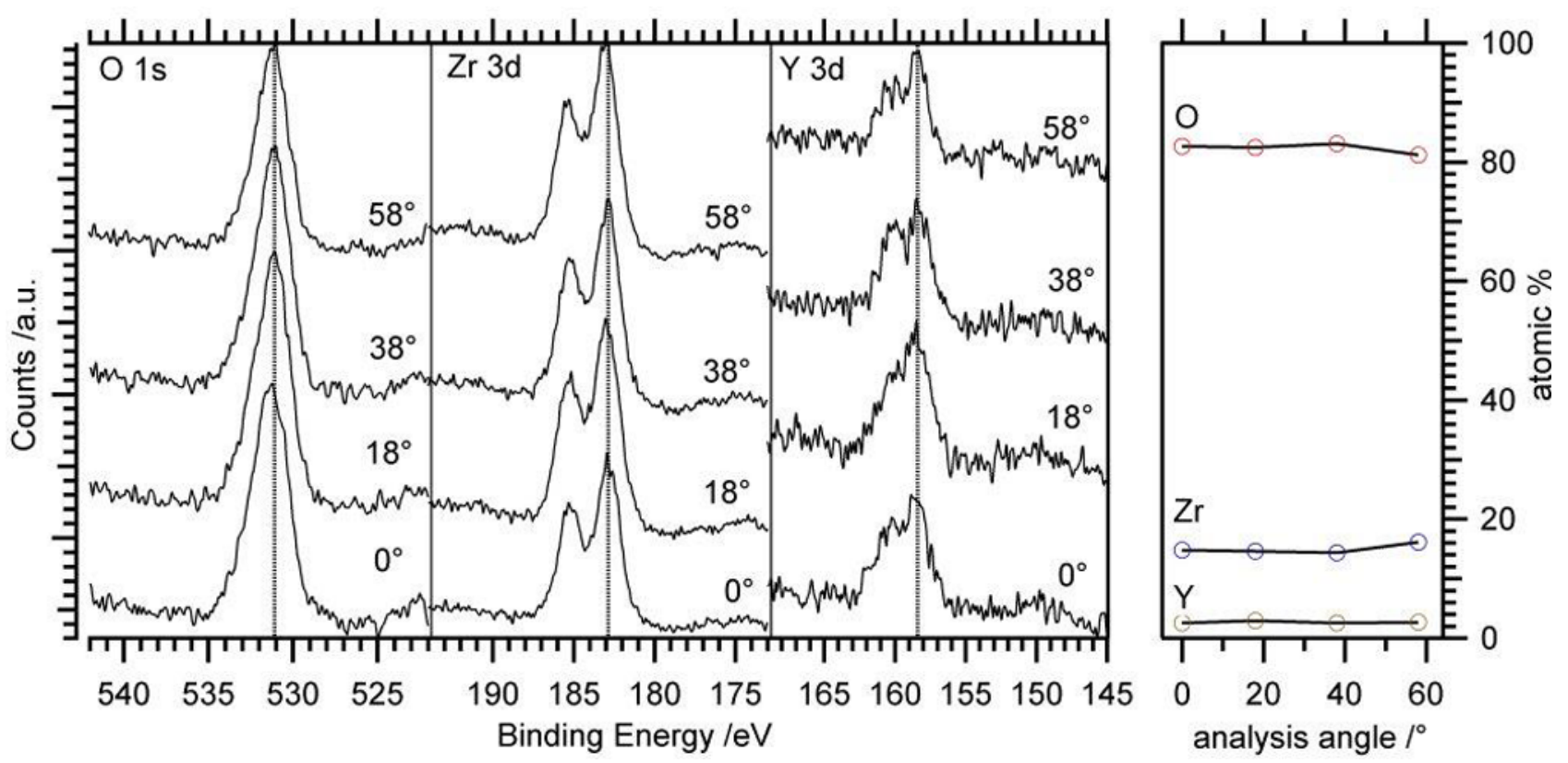

Figure 2: Angle-resolved XPS at different analysis angles from $0^{\circ}$ to $58^{\circ}$, indicating different sample depths. Left: O 1s, Zr 3d and $\mathrm{Y}$ 3d signals, right: plot of the concentration variation of $\mathrm{O}, \mathrm{Zr}$ and $\mathrm{Y}$ with the analysis depth.

$\mathrm{BE}$ shifts for any of the peaks have been observed, irrespective of the analysis angle. This indicates that the valence states of $\mathrm{O}, \mathrm{Y}$ and $\mathrm{Zr}$ do not substantially depend on the sample depth, indicating an electronically and chemically homogenous sample. Secondly, as the content of O, $\mathrm{Zr}$ and Y basically stays constant over the analyzed sample depth, we infer a homogeneous distribution of $\mathrm{Y}$ within the sampled region. This is corroborated by the EFTEM results (cf. Figure 3), which also reveal a corresponding homogeneous Y distribution. Combination of the information from angle-resolved XPS (surface-near regions) and electron microscopy (bulk) indicates that the $\mathrm{Y}$ distribution basically is invariant of the sample depth.

The homogeneity has not only been checked in the depth-dimension by means of XPS, but also laterally via energy-filtered TEM (EFTEM). Details of a core-loss EEL spectrum of a TEM specimen prepared at a substrate temperature of $353 \mathrm{~K}$, featuring the ionization edges of yttrium as well as zirconium, is shown in Figure 3 (a). The $\mathrm{Y} \mathrm{L}_{3}$ edge is found at around $2080 \mathrm{eV}$, the $\mathrm{Zr} \mathrm{L}_{3}$ analogue at $2222 \mathrm{eV}$, and the $\mathrm{Zr} \mathrm{L}_{2}$ edge starts at $2308 \mathrm{eV}$, which fits the corresponding literature values for the oxidic species.[40] The $\mathrm{L}_{3} / \mathrm{L}_{2}$ white line intensity ratio, which was determined to be 1.3 , corresponds well with the value obtained if the same procedure is applied to a core-loss spectrum of $\mathrm{ZrO}_{2}$ from the literature, also yielding a value of 1.3.[41] This indicates that the oxidation states are the same in both cases. The $\mathrm{Y} \mathrm{L}_{3}$-edge was subsequently used to generate an yttrium map by use of EFTEM, which can be seen in Figure 3 (b) as a false-coloring of the zero-loss filtered bright field image. The even distribution of blue in this image indicates a laterally homogeneous distribution of yttrium. 

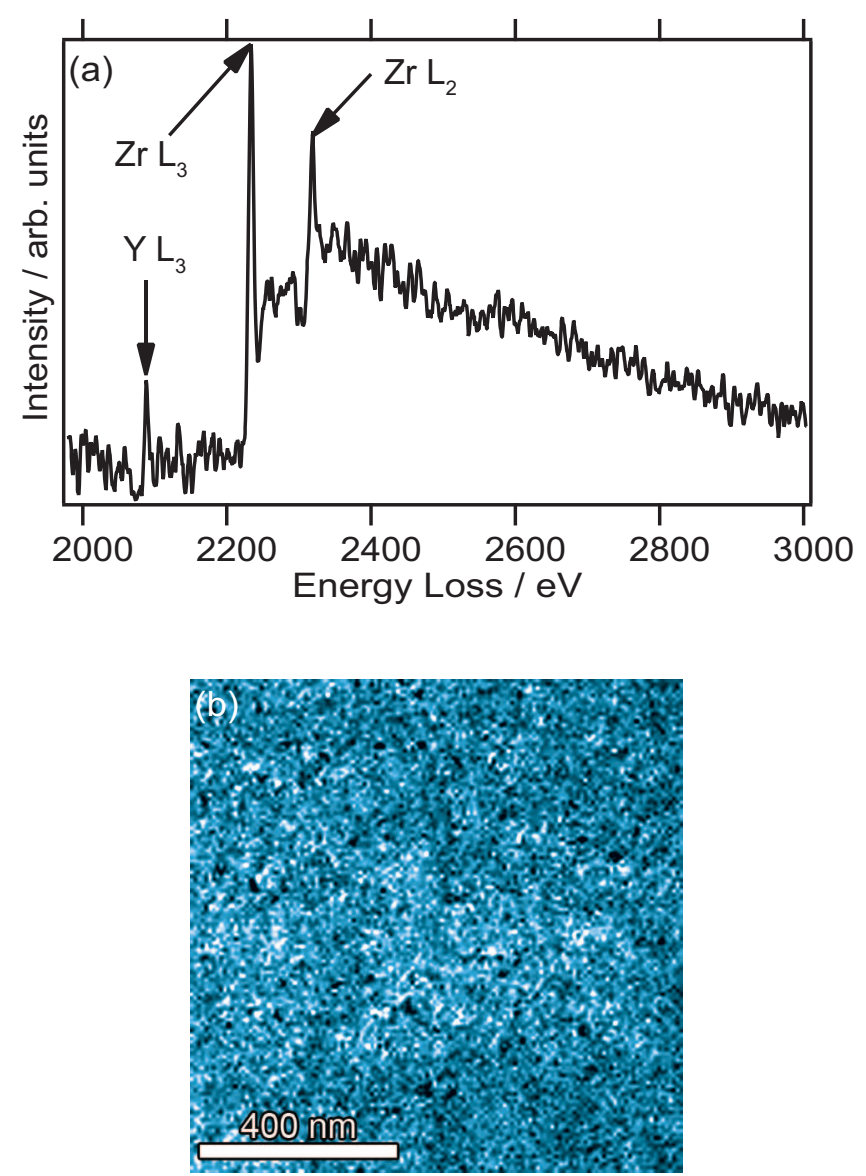

Figure 3: (a) Core-Loss EEL spectrum showing $\mathrm{Y} \mathrm{L}_{3}$ and $\mathrm{Zr} \mathrm{L}_{2} / \mathrm{L}_{3}$ edges. (b) False-colored EFTEM image recorded using the $\mathrm{Y} \mathrm{L}_{3}$ edge, used to color the zero-loss bright field image of the sample deposited at $353 \mathrm{~K}$.

The low-loss region in the EEL spectra, containing the plasmon peaks as well as the $\mathrm{Zr} \mathrm{N}_{23}$ and $\mathrm{Y} \mathrm{N}_{23}$ signals and, hence, being suitable as fingerprint for a respective structure, was also analyzed (see Figure 4, the spectra have been corrected for plural scattering). Figure 4 (a) shows the effect of the substrate temperature as it contains the spectra for the as-grown samples at different deposition temperatures, compared to a reference spectrum of tetragonal YSZ (with $8 \% \mathrm{Y}_{2} \mathrm{O}_{3}$ ) powder used for the preparation of the sputtering target. Comparing the plasmon peaks, the height of the first peak increases relative to that of the second one when the substrate temperature is raised from $353 \mathrm{~K}$ to $623 \mathrm{~K}$. Due to this shift in intensity, the spectrum obtained for the specimen sputtered at higher temperatures resembles the reference EELS more than the one deposited at lower temperature, even though the intensity ratio of the first two peaks is still far from that found for the commercial powder. This indicates that the YSZ thin film is possibly prepared in a somewhat defective state (e.g. containing O-vacancies) at lower temperatures, which can already be healed out somewhat during deposition by increasing the substrate temperature.

Figure 4 (b) shows the spectra for the specimens deposited at $623 \mathrm{~K}$ in their as-grown state, as well as 

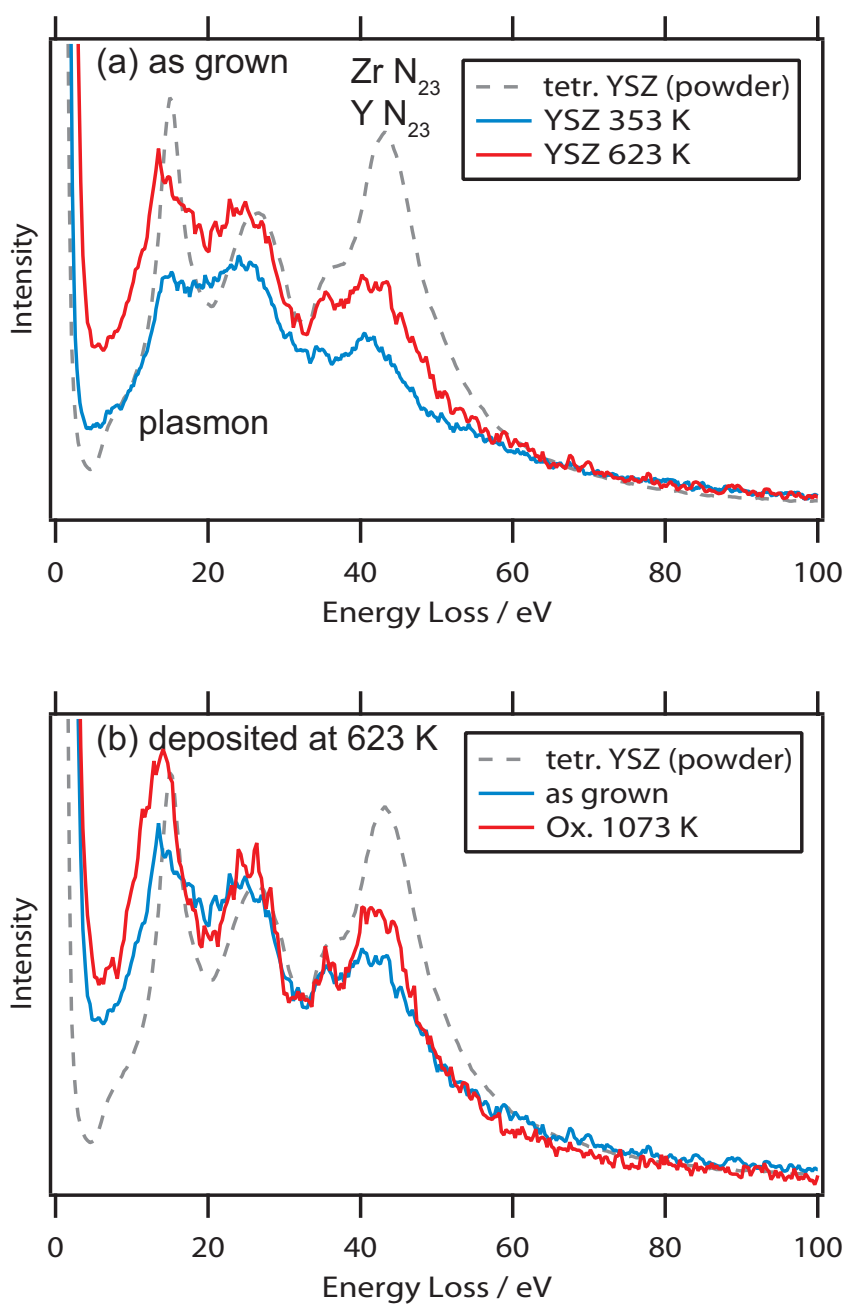

Figure 4: Low-loss EELS in dependence of (a) the deposition temperature and (b) the post-deposition oxidation for the sample sputtered at $493 \mathrm{~K}$ compared to the reference spectrum for tetragonal YSZ (powder sample).

after oxidation at $1073 \mathrm{~K}$. It can be seen that, once the sample is post-treated in air at $1073 \mathrm{~K}$, the plasmon region changes drastically compared to the as grown sample, and now closely follows the one obtained for the reference YSZ powder. This would suggest that, indeed, the samples are grown defective, but also that this can either be steered to some extent by raising the substrate temperature, or almost completely suppressed by oxidizing the samples at $1073 \mathrm{~K}$.

Figure 5 provides exemplary HAADF images of two samples deposited at $493 \mathrm{~K}$ - one in the as-grown state (a) and the other one after oxidation at $1073 \mathrm{~K}(\mathrm{~b})$. Both show no inhomogeneities related to $\mathrm{Y}$ distribution. The contrast is basically due to thickness variations resulting from the grain growth during the sputtering process. 

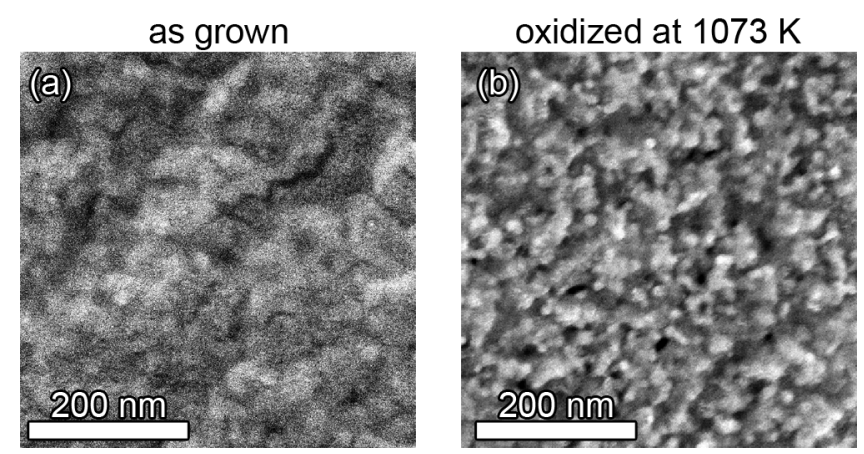

Figure 5: HAADF images of samples deposited at $493 \mathrm{~K}$, in (a) the as-grown state and (b) after oxidation at $1073 \mathrm{~K}$.

\subsection{Crystallization Behaviour}

Bright field overview images of the YSZ thin films can be seen in Figure 6. The left column ((a), (c), (e)) shows the specimen in the as-grown state, while images (b), (d) and (f) on the right side were recorded after oxidation in air at $1073 \mathrm{~K}$. The micrographs of the as-grown samples all feature Bragg contrast typical of crystalline samples (and, in fact, they all are crystalline as shown in Figure 7). Upon post-deposition annealing, however, pronounced effects of sintering are visible. This can be seen best for the specimen sputtered at a substrate temperature of $353 \mathrm{~K}$ (top row), which only shows a few dark grains without posttreatment (a), but, after oxidation, the grain-boundaries are clearly visible (b). Similar observations can also be made for the transition from the sample grown at $493 \mathrm{~K}$ (c) to its oxidized variant (d), as well as for that deposited at $623 \mathrm{~K}((\mathrm{e})$ and $(\mathrm{f}))$.

In fact, comparing this to the HAADF images of samples sputtered on substrates heated to $493 \mathrm{~K}$ in Figure 5, an analogous change in morphology can be seen: upon oxidation in air, the formerly large and rather round grains (a) transform to smaller, more dendritic crystallites. What we can, however, not observe in our specimens is pinhole formation as described by Gorman and Anderson, [42] who found that pinholes were more likely to appear if the YSZ films were annealed in their unsupported state, as is the case with our samples.[42] This could, however, be readily explained by both, the different preparation method they used, as their films were prepared using spin coating on a single-crystalline $\mathrm{NaCl}$ substrate, as well as the different composition, as they state that their samples contain $16 \%$ of $\mathrm{Y}$, which would amount to about $30 \mathrm{~mol} \% \mathrm{Y}_{2} \mathrm{O}_{3}$.

From the bright field images, it can be deduced that all samples, irrespective of the deposition temperature, are crystalline, as the selected area diffraction patterns in Figure 7 also reveal. For the as-grown specimen sputtered at $353 \mathrm{~K}$, shown in (a), a Debye-Scherrer type ring pattern, characteristic of nanocrystalline materials, can be observed. The most intense and centermost ring is composed of spots arising from the (101) lattice planes with a spacing determined experimentally to be $0.295 \mathrm{~nm}$, compared to a theoretical value of $0.296 \mathrm{~nm}$. The neighboring ring, already with a strongly decreased intensity, arises from the 

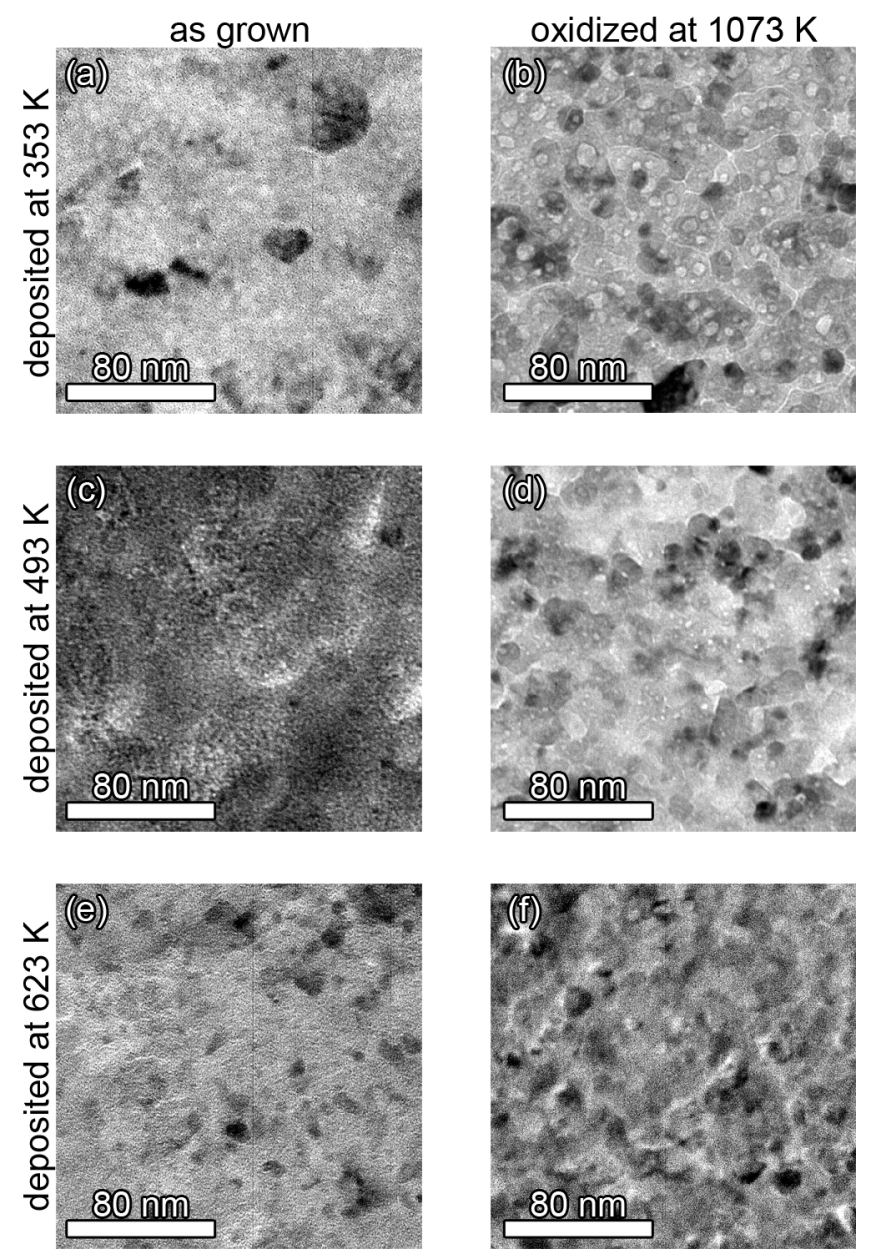

Figure 6: Bright field TEM images of samples grown at various substrate temperatures in the as-grown state ((a), (c) and (e)) and their counterparts after oxidation at high temperature $(1073 \mathrm{~K},(\mathrm{~b}),(\mathrm{d})$ and (f)).

(002) and (110) lattice planes, both featuring a lattice spacing of $0.256 \mathrm{~nm}(0.263 \mathrm{~nm}$ in this diffraction pattern).[43]

After oxidation at $1073 \mathrm{~K}$, the SAED pattern highlighted in Figure 7 (b) resembles that of the as-grown sample as it also features rings. However, within the rings, more individual spots can be discerned. This increased spottiness of the signals indicates an increase in crystallite size. This goes along with the features seen in the bright field images presented in Figure 6, where the effects of sintering could be observed clearly. The marked rings stem from the (101) planes (with an experimentally determined lattice spacing of $0.299 \mathrm{~nm}$ ), as well as the (200) and (112) planes (found at $d_{\text {exp. }}=0.182 \mathrm{~nm}$ ), which both feature a theoretical lattice spacing of $0.182 \mathrm{~nm} .[43]$

If the deposition temperature is raised from $353 \mathrm{~K}$ to $493 \mathrm{~K}$, the SAED pattern in Figure 7 (c) is obtained for the as-grown sample. It features clearly defined spots, indicating a high degree of ordering in this 

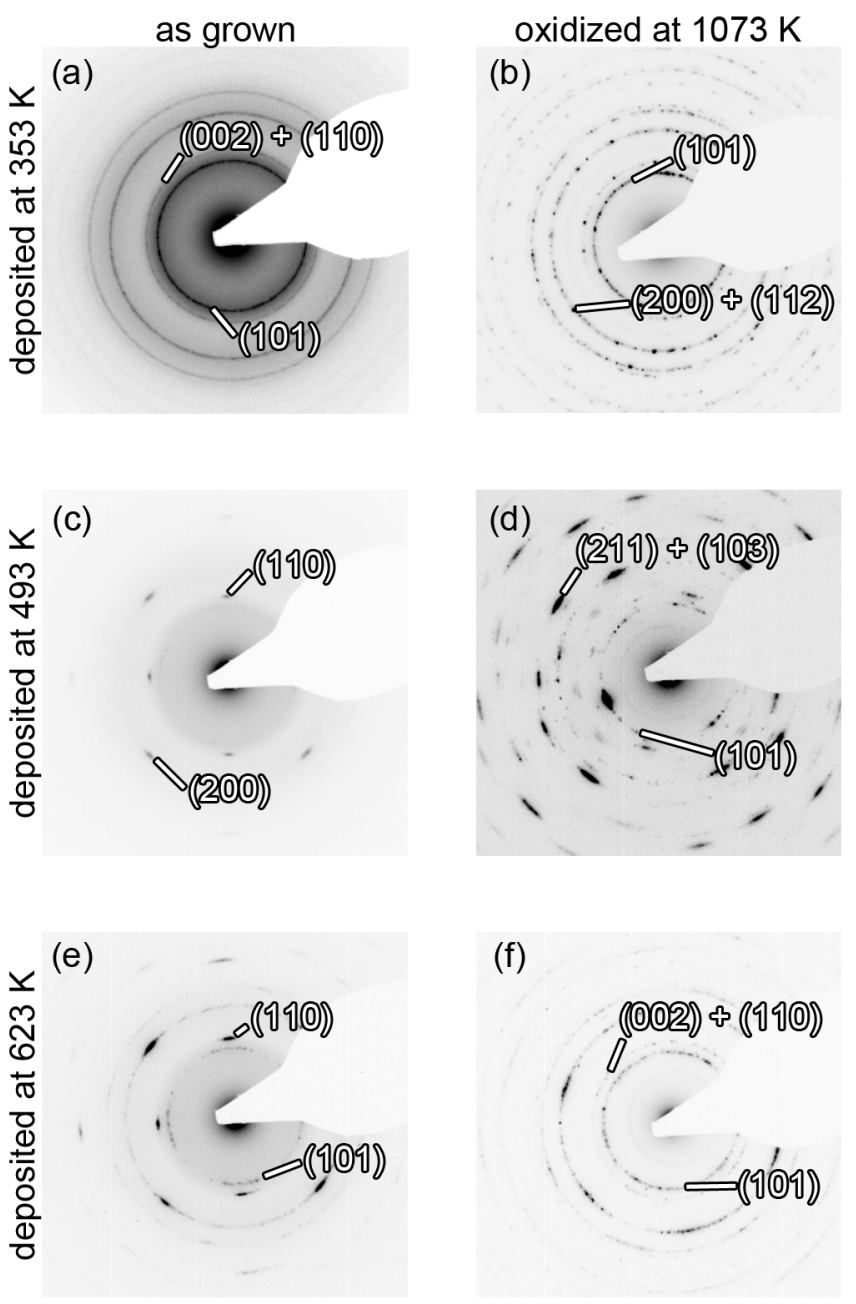

Figure 7: SAED patterns corresponding to the bright field images in Figure 6. (a), (c), (e) as grown, (b), (d), (f) after oxidation.

specimen. The complete absence of rings between the spots show that, at this substrate temperature, YSZ can be grown epitaxially on a $\mathrm{NaCl}(001)$ facet. The spots indicated in the image can be attributed to the (110) and (200) lattice planes (with spacings measured to be $0.256 \mathrm{~nm}$ and $0.182 \mathrm{~nm}$, respectively), the angle between which is measured to be $45^{\circ}$, as to be expected from its crystal structure.[43] Hence, the sample is essentially oriented along its [001] zone axis. Again, annealing the sample at $1073 \mathrm{~K}$ (d) causes the specimen to become more polycrystalline, as revealed by the appearance of spotty ring patterns in-between the more intense spots. The existence of these spots, however, indicates that no complete loss of texturing of the thin film is caused by this post-deposition treatment. What is interesting is that the ring that is attributable to either the (211) or the (103) lattice planes (with a theoretical spacing of $0.155 \mathrm{~nm},[43]$ and a measured one of $0.157 \mathrm{~nm}$ ) shows intense spots, suggesting that its contributing crystallites still feature a strong texturing. However, neither the (211)-, nor the (103)-spots belong to the [001] zone axis found for the as-grown sample 
grown epitaxially. This suggests that, during the sintering process, a tilting of the crystallites to another zone axis must be energetically favorable. This is also corroborated by the fact that the (101) and (102) signals (the latter at $0.215 \mathrm{~nm}$, as compared to a theoretical value of $0.210 \mathrm{~nm}$ ),[43] both also not appearing in [001]-oriented crystallites, show well-defined spots as well.

If the substrate temperature during the sputtering process is increased to $623 \mathrm{~K}$, the film is again deposited epitaxially (see the SAED pattern (e) in Figure 7). However, in this diffraction pattern, the rings typical of polycrystalline materials can already be seen slightly for the sample in the as-grown state. The (110) $\operatorname{spots}\left(d_{\text {exp. }}=0.258 \mathrm{~nm}\right)$, for instance, are visible as discrete spots, whereas the (101) signals at $0.298 \mathrm{~nm}$, not found in a zone axis that would allow epitaxial growth on $\mathrm{NaCl}(001)$, evidently arise from disordered crystallites since no texture can be recognized in this ring. If the sample is oxidized at $1073 \mathrm{~K}$ (f), it, transforms to a more polycrystalline thin film, too. However, in contrast to the sample deposited at $493 \mathrm{~K}$, the preservation of the crystallite ordering is less pronounced, for only the (200) ring still contains strong reflections.

The generally very good agreement between the experimental lattice spacings and the theoretical values (obtained for the compound of the same composition $\left(8 \mathrm{~mol} \% \mathrm{Y}_{2} \mathrm{O}_{3}\right)$ ) - both for the as-grown, as well as the annealed samples - indicates that the lattice strain due to the growth on the $\mathrm{NaCl}$ substrate is not very pronounced for our samples.

In addition to SAED, HRTEM images have been recorded to further analyze the crystallites, two examples of which are shown in Figure 8. (a) shows a HRTEM image of an as-grown sample deposited at $493 \mathrm{~K}$, while the specimen used to record (b) was oxidized at $1073 \mathrm{~K}$. The image in (a) allows the determination of the lattice spacings in three directions: the distance between the almost-vertical lattice fringes can be measured to be $0.29 \mathrm{~nm}$, which corresponds to the (101) lattice planes (with a theoretical value of $0.296 \mathrm{~nm}$ ).[43] The spacing of $0.29 \mathrm{~nm}$ is then attributable to the (101) planes (with the same spacing as the (101) ones). And the fringes running from the top left to the lower right in the image have a distance of $0.26 \mathrm{~nm}$ between them and arise due to the (002) lattice planes (with $d_{\text {theo. }}=0.256 \mathrm{~nm}$ ). [43] The angles between the planes agree nicely with theoretical values, too: the angle between (002) and (101) is measured to be $52.6^{\circ}$ (theory: $54.8^{\circ}$ ), while the one between (002) and (101) is $55.7^{\circ}$ in the image (and $54.8^{\circ}$ as calculated from the crystal structure), and the (101) and (101) planes span an angle of $68.7^{\circ}$ in the experiment and $70.4^{\circ}$ in theory.

In (b), another grain can be seen, which was heated to $1073 \mathrm{~K}$. Here, the smallest of the marked lattice spacings with $0.26 \mathrm{~nm}$ can be attributed to the (002) planes (which, in theory, are $0.256 \mathrm{~nm}$ apart).[43] The fringes with $0.29 \mathrm{~nm}$ spacings, on the other hand, stem from the (101) as well as the (101) lattice planes $\left(d_{\text {theo. }}=0.296 \mathrm{~nm}\right)$. The angles between these fringes correlate well with calculated values: $(002)$ and (101) span an angle of $54.5^{\circ}$ (theory: $54.8^{\circ}$ ), while the angle between (101) and (101) is $68.8^{\circ}$ (and $70.4^{\circ}$ theoretically), and between (101) and (002), $56.7^{\circ}$ can be measured, which nicely fits the theoretical $54.8^{\circ}$. In both, the micrograph of the as-grown sample in (a), as well as the image of the oxidized sample (b), the 

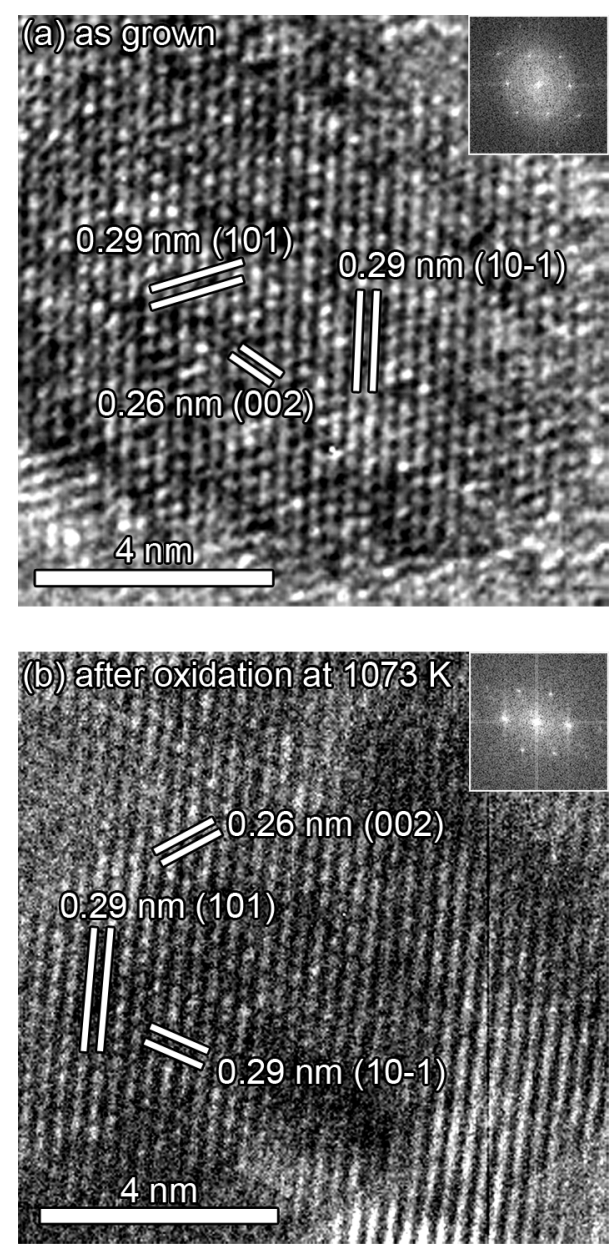

Figure 8: Examples of HRTEM images of YSZ-crystallites as deposited at $493 \mathrm{~K}$ (a) and after post-deposition annealing at $1073 \mathrm{~K}$ (b) with the respective FFTs as insets.

zone axis of the imaged crystallite can be determined to be along the [010] direction.

\subsection{Surface Morphology}

To get complimentary information to the TEM images, which represent a projection of the whole thin film structure to two dimensions, AFM images were taken for each TEM sample using intermittent contact mode, yielding surface topological data. Figure 9 shows these scanning probe micrographs (all with dimensions of $1 \mu \mathrm{m} \times 1 \mu \mathrm{m})$ in dependence of the substrate temperature during sputtering, as well as the post-deposition oxidation temperature. For each sample, two images are given: the left one shows the topography (with the text inset showing the total height span), and the right image represents the phase information, which shows changes in sample-tip interactions (the $z$-value denotes the total phase variation in the image).

In (a), the YSZ thin film that was sputtered at $353 \mathrm{~K}$ is shown in its as-grown state. The topography (left) shows a net-like structure, with four distinct grains sitting on top of the film. The phase signal (right) 

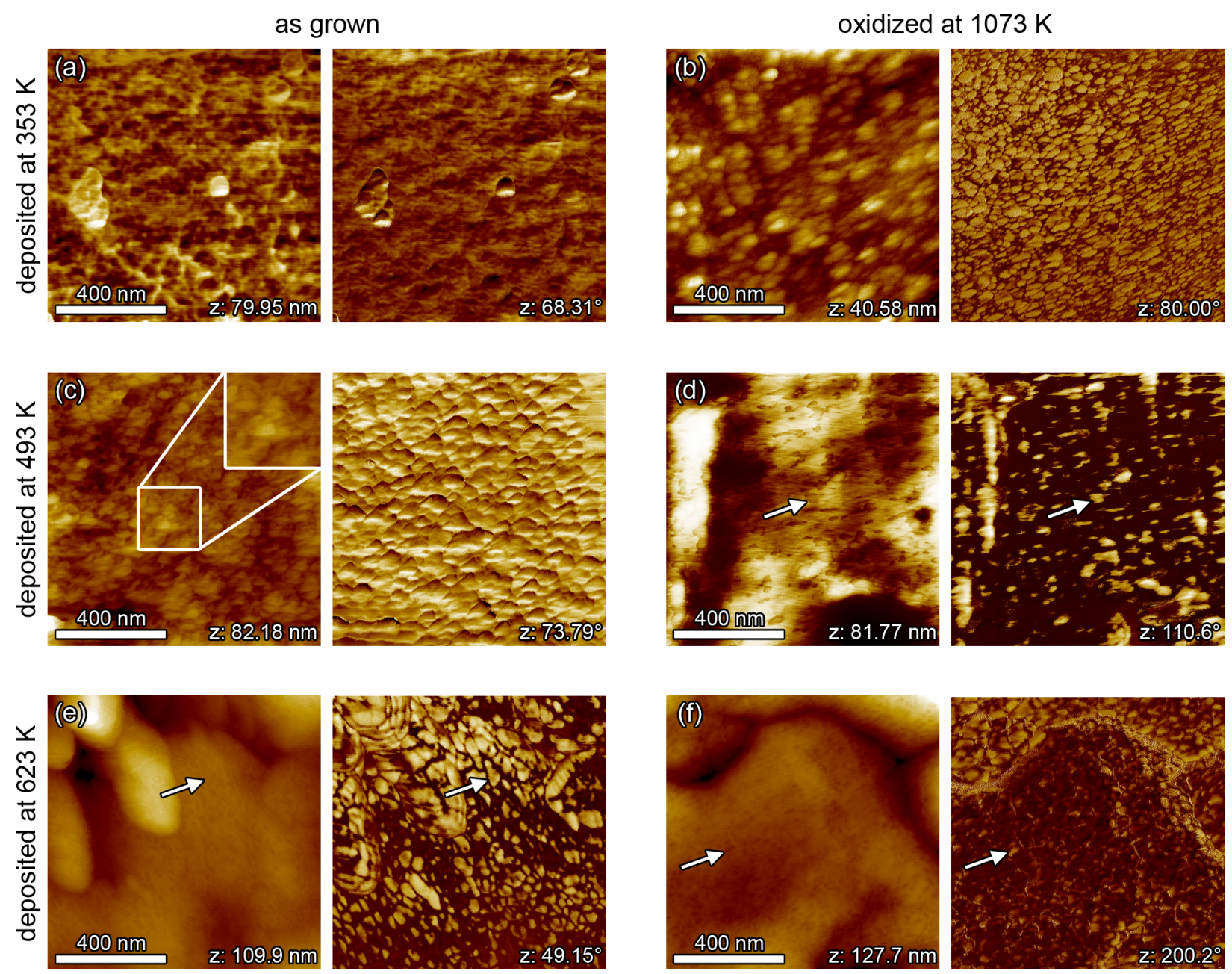

Figure 9: AFM images of the YSZ specimens used for the TEM investigations. Each pair of micrographs consists of the topography (left) and the phase signal (right). The image dimensions are $1 \mu \mathrm{m} \times 1 \mu \mathrm{m}$.

indicates the existence of rather large grains within the film (as visible in the lower part of the image). Upon post-annealing at $1073 \mathrm{~K}(\mathrm{~b})$, the surface morphology changes drastically. The net-pattern has vanished, and well-defined grains are visible instead. The phase signal especially reveals the large number of crystallites found on the surface. This agrees nicely with the bright field images in Figure 6, which showed that pronounced sintering occurs during oxidation.

Image (c) shows a specimen sputtered at $493 \mathrm{~K}$, featuring overlapping triangularly-shaped grains (see inset), as visible in the topography. The net-like structure seen in (a) is absent, although the phase signals resemble that of the sample prepared at $353 \mathrm{~K}$, only with stronger contrast. Once the sample was exposed to $1073 \mathrm{~K}$, the surface morphology changed to that seen in (d). The topography contains small "recesses", which correspond to the bright spots seen in the phase signal. An example of such a correlation is marked by arrows. This means that, in these dips, the interaction with the sample is altered as compared to the 
surrounding areas. Since the HAADF images showed no inhomogeneities at this post-treatment stage, a change in interaction due to a precipitation of, e.g., yttrium oxide can be excluded. Thus, it is more likely that the features visible in the phase correspond to grains, as was the case in, for instance, (b). This would, however, mean that the grains have somehow sunk into the surface slightly, which could be explained by the sintering process that is evident in the HAADF, as well as the bright field micrographs, as the tilting of the crystallites as deduced from the SAED patterns might have resulted in the apparent recession of these grains.

The sample seen in (e) was deposited at a substrate temperature of $623 \mathrm{~K}$. The topography also features a multitude of small "recesses" in the surface - even more than the oxidized sample (deposited at $493 \mathrm{~K}$ ) in (d) did. These recesses, again, correlate nicely with the bright spots in the phase images, as evidenced by the locations the arrows point to. In this as-grown specimen, the density of these dips is much higher than it was in the previous micrograph. Again, judging from the good correlation with the phase signal, the recesses seem to stem from crystallites. However, for the as-grown sample, it is not possible to explain their occurrence by means of a sintering process, albeit it could correlate with the increased polycrystallinity exhibited by this sample (see the SAED patterns in Figure 7) as compared to the one sputtered at $493 \mathrm{~K}$. When oxidized at $1073 \mathrm{~K}$ (f), the surface structure, in principle, is retained, as the same types of recesses can be seen in the topography at the same spots as the bright areas appear in the phase image.

Table 1: RMS surface roughness values of the various samples in their as-grown state, as well as after post-deposition oxidation at $1073 \mathrm{~K}$, as determined by AFM.

Deposition Oxidation RMS Surface

\begin{tabular}{ccc} 
Temperature / K & Temperature / K & Roughness / nm \\
\hline \multirow{2}{*}{353} & - & 9.6 \\
& 1073 & 4.9 \\
\hline \multirow{2}{*}{493} & - & 7.5 \\
& 1073 & 8.8 \\
\hline \multirow{2}{*}{623} & - & 13.7 \\
& 1073 & 13.8 \\
\hline
\end{tabular}

In order to quantify the surface morphological changes, the root-mean square (RMS) surface roughness value was determined for the topography images. Table 1 lists these roughness data. From this table, it can be seen that an increase of the substrate temperature from $353 \mathrm{~K}$ to $493 \mathrm{~K}$ during deposition causes decrease of the RMS surface roughness, dropping from $9.6 \mathrm{~nm}$ to $7.5 \mathrm{~nm}$. Upon further raising the substrate temperature to $623 \mathrm{~K}$, however, the value increases again drastically (to $13.7 \mathrm{~nm}$ ). Looking at the topography in Figure 9 (e), the reason for this increase is that large grains are visible therein. Since the maximum $z$-span 
in the image is almost $110 \mathrm{~nm}$, compared to $82 \mathrm{~nm}$ for the sample deposited at $493 \mathrm{~K}$, this influences the RMS surface roughness. This is corroborated by the fact that the RMS surface roughness value drops to $8.4 \mathrm{~nm}$ if the upper left quadrant of the image is omitted in the calculation.

When oxidized at $1073 \mathrm{~K}$, the surface roughness value of the specimen deposited at $353 \mathrm{~K}$ in its as-grown state decreases by almost $50 \%$ to $4.9 \mathrm{~nm}$. Again, the reason could be the four distinctly visible grains on top of the film increasing the calculated RMS surface roughness value, while the oxidized sample looks rather flat (with a $z$-span of only $40.6 \mathrm{~nm}$ ). For the sample sputtered at $493 \mathrm{~K}$, the roughness value increases slightly from $7.5 \mathrm{~nm}$ to $8.8 \mathrm{~nm}$, which is most likely due to the deep dip at the lower edge of the image, which probably is a tear within the free-standing film. Omitting this area from the topography used for the calculation yields a RMS value of just $3.6 \mathrm{~nm}$. For the sample deposited at $623 \mathrm{~K}$, there is not much change in the roughness $(13.8 \mathrm{~nm}$ compared to $13.7 \mathrm{~nm}$ ). This goes hand in hand with both the surface topography (Figure 9), as well as the TEM bright field images (Figure 6), as both do not show any significant alterations of the morphologies.

In published literature, AFM analyses of YSZ films are sparse. For instance, Pandey et al. investigated approximately $250 \mathrm{~nm}$ thick films prepared on quartz using pulsed laser deposition. They found the surface roughness to increase with the substrate temperature, which they ascribed to crystallization phenomena.[15] In our case, on the other hand, the roughness shows no clear trend, which is most likely due to the large grains and "folds" of our samples, which is a result of the free-standing nature of our thin films. If such areas are omitted from the calculations, we find that our surface roughness actually decreases with the substrate temperature. This can be explained by the difference in deposition methods: whereas the sample is evaporated in PLD, creating films with a smooth topology at low temperature, as seen in the micrographs by Pandey et al.,[15] further crystallization causes more grains to appear when the substrate temperature is raised. In the case of sputtering, we use a crystalline target that is not evaporated, but clusters are sputtered off; hence, we already generate crystalline samples at substrate temperatures as low as $353 \mathrm{~K}$. And an increase in deposition temperature will probably allow our film to relax somewhat, creating a smoother surface.

Cavallaro et al. also used PLD to prepare their films, which are $5 \mathrm{~nm}$ in thickness, but still placed on their substrate, which was a $\mathrm{SrTiO}_{3}$ perovskite with controlled $\mathrm{SrO} / \mathrm{TiO}_{2}$ termination. [12] For these samples, the thin film deposited on the purely- $\mathrm{TiO}_{2}$-terminated perovskite resembles our specimens most, in that it features a rather grainy surface, albeit with a much smaller grain size. Their films become smoother with an increasing SrO-termination ratio, becoming atomically flat with dominant terraces.[12] The PLD-thin films prepared at various oxygen-pressures by Shin et al., on the other hand, resemble our films deposited at lower temperatures (Figure 9 (a) to (c)).[44]

Thin films created by spray pyrolysis at various substrate temperatures were imaged by Garcia-Sánchez et al.[18] The sample prepared at the highest temperature, where the solvent was already evaporated before 
it reached the surface, resulting in dry particles reaching the substrate during deposition, looks most alike to the images presented in this work, which is comprehensible since, when sputtering, small particles or clusters reach the surface as well - hence the similarities in the images.

Green et al. investigated YSZ(001) single crystals via AFM and also found high densities of pits on their surfaces. However, they find that, unlike in our case, the pits vanish after annealing (albeit to a higher temperature of $1673 \mathrm{~K}$ ). Still, the mechanism they discuss seems to be relevant for our samples: due to an initial presence of F-center defects (e.g. the already-discussed oxygen vacancies), preferential diffusion at these cites causes the recesses to appear.[45] This agrees nicely with the fact that we only see the pits at higher deposition temperatures and after thermal annealing, which could both initiate the diffusion processes. At first sight, this seemingly contradicts the conclusion from earlier (see the low loss EELS in Figure 4) that the defects can be healed by higher temperatures. However, it is possible that this diffusion, which only occurs at higher temperatures, is the cause for the reduction of these defects, causing the plasmon peaks to resemble the reference spectrum more closely.

\section{Conclusion}

We have shown that, using freshly-cleaved $\mathrm{NaCl}(001)$ faces as substrates, tetragonal YSZ thin films can be grown epitaxially by means of sputtering if the temperature is raised above $493 \mathrm{~K}$. In these cases, the crystallites are textured predominantly along the [001] zone axis. If the samples are oxidized at $1073 \mathrm{~K}$ in air, strong effects of sintering can be observed in the bright field TEM images as well as the diffraction patterns (which change to Debye-Scherrer-like patterns with discrete spots characteristic for polycrystalline samples with large grain sizes).

The homogeneity of the films was proven in both the depth, as well as in lateral dimensions by angleresolved XPS and EELS/EFTEM, with neither showing any Y segregation. Also, HAADF micrographs revealed only thickness variations due to the crystallization process (with the crystallites being visible clearly), but no change due to $Z$-contrast. Measuring the $\mathrm{L}_{3} / \mathrm{L}_{2}$ white line intensity ratio from the core-loss EELS, the same value could be obtained as in a reference spectrum from the literature, which corroborates the results from the XPS, where the analysis of chemical shifts indicated that the YSZ is fully oxidized. The low-loss region, however, containing the plasmon fingerprints and the $\mathrm{Zr} \mathrm{N}_{23}$ edges, revealed a strong dependence on both the substrate temperature during deposition, as well as on the post-deposition annealing. If this region is compared to a spectrum from the literature, it is revealed that, with increasing deposition temperature, the spectra match each other. And once the specimens are oxidized at $1073 \mathrm{~K}$, the resulting low-loss EELS is almost identical to the reference spectrum.

AFM was utilized to investigate the surface morphology for all samples. The sintering deduced from the bright-field images is also visible in the surface topography, with the crystallites seemingly being recessed 
during polycrystallization either visible upon oxidizing the sample deposited at $493 \mathrm{~K}$, or in the as-grown sample sputtered at $623 \mathrm{~K}$ (as well as in its post-treated analogue), where the phase image shows bright spots of the same shape in the same locations as the topography reveals recessed pits.

As for technological applications of the YSZ films, we envision a potential use as, e.g., catalysts due to their high thermal and structural stability and unsupported nature. YSZ films, so far, suffer from the presence of an oxide-oxide or oxide-metal interface, depending on which substrate material is used. Although not per se detrimental, the deliberate occurrence of this interface complicates the characterization of the pure YSZ material. This can be conveniently overcome by the YSZ films presented here.

\section{Acknowledgments}

This work was financially supported by the Austrian Science Fund (FWF) through grant F4503-N16 and has been performed within the framework of the Forschungsplattform Materials and Nanoscience.

\section{References}

[1] T. H. Etsell, S. N. Flengas, Electrical properties of solid oxide electrolytes, Chem. Rev. 70 (3) (1970) $339-376$. doi:10.1021/cr60265a003.

[2] Steele, Brian C. H., A. Heinzel, Materials for fuel-cell technologies, Nature 414 (6861) (2001) 345-352. doi:10.1038/35104620.

[3] B. Hobein, F. Tietz, D. Stöver, M. Čekada, P. Panjan, DC Sputtering of yttria-stabilised zirconia films for solid oxide fuel cell applications, J. Eur. Ceram. Soc. 21 (10-11) (2001) 1843-1846. doi:10.1016/S0955-2219(01) 00127-3.

[4] J. S. Lamas, W. P. Leroy, Y.-G. Lu, J. Verbeeck, G. van Tendeloo, D. Depla, Using the macroscopic scale to predict the nano-scale behavior of YSZ thin films, Surf. Coat. Technol. 238 (2014) 45-50. doi:10.1016/j.surfcoat.2013.10.034.

[5] R. Frison, S. Heiroth, J. Rupp, K. Conder, E. J. Barthazy, E. Müller, M. Horisberger, M. Döbeli, L. J. Gauckler, Crystallization of $8 \mathrm{~mol} \%$ yttria-stabilized zirconia thin-films deposited by RF-sputtering, Solid State Ionics 232 (2013) 29-36. doi:10.1016/j.ssi.2012.11.014.

[6] A. F. Jankowski, Sputter deposition of yttria-stabilized zirconia onto a porous Au substrate, J. Vac. Sci. Technol, A 13 (3) (1995) 658. doi:10.1116/1.579802.

[7] D. E. Ruddell, B. R. Stoner, J. Y. Thompson, The effect of deposition parameters on the properties of yttria-stabilized zirconia thin films, Thin Solid Films 445 (1) (2003) 14-19. doi:10.1016/j.tsf.2003.07.009.

[8] S. Sønderby, A. Aijaz, U. Helmersson, K. Sarakinos, P. Eklund, Deposition of yttria-stabilized zirconia thin films by high power impulse magnetron sputtering and pulsed magnetron sputtering, Surf. Coat. Technol. 240 (2014) 1-6. doi:10.1016/j.surfcoat.2013.12.001.

[9] E. S. Thiele, L. S. Wang, T. O. Mason, S. A. Barnett, Deposition and properties of yttria-stabilized zirconia thin films using reactive direct current magnetron sputtering, J. Vac. Sci. Technol, A 9 (6) (1991) 3054. doi:10.1116/1.577172.

[10] R. Nédélec, S. Uhlenbruck, D. Sebold, V. Haanappel, H.-P. Buchkremer, D. Stöver, Dense yttria-stabilised zirconia electrolyte layers for SOFC by reactive magnetron sputtering, J. Power Sources 205 (2012) $157-163$. doi:10.1016/j.jpowsour.2012.01.054.

[11] J. Y. Paek, I. Chang, J. H. Park, S. Ji, S. W. Cha, A study on properties of yttrium-stabilized zirconia thin films fabricated by different deposition techniques, Renewable Energy 65 (2014) 202-206. doi:10.1016/j.renene. 2013.08.043. 
[12] A. Cavallaro, B. Ballesteros, R. Bachelet, J. Santiso, Heteroepitaxial orientation control of YSZ thin films by selective growth on SrO-, TiO2-terminated SrTiO3 crystal surfaces, CrystEngComm 13 (5) (2011) 1625. doi:10.1039/c0ce00606h.

[13] I. Kosacki, C. Rouleau, P. Becher, J. Bentley, D. Lowndes, Nanoscale effects on the ionic conductivity in highly textured YSZ thin films, Solid State Ionics 176 (13-14) (2005) 1319-1326. doi:10.1016/j.ssi.2005.02.021.

[14] Z. Ouyang, T.-S. Cho, D. N. Ruzic, Deposition of YSZ Thin Films by Atmospheric Plasma-Assisted Pulsed Laser Ablation, IEEE Trans. Plasma Sci. 40 (11) (2012) 2850-2852. doi:10.1109/TPS. 2012.2213099.

[15] S. K. Pandey, O. P. Thakur, R. Raman, A. Goyal, A. Gupta, Structural and optical properties of YSZ thin films grown by PLD technique, Appl. Surf. Sci. 257 (15) (2011) 6833-6836. doi:10.1016/j.apsusc. 2011.03.008.

[16] K. Rodrigo, J. Knudsen, N. Pryds, J. Schou, S. Linderoth, Characterization of yttria-stabilized zirconia thin films grown by pulsed laser deposition (PLD) on various substrates, Appl. Surf. Sci. 254 (4) (2007) $1338-1342$. doi:10.1016/j.apsusc.2007.07.194.

[17] Schlupp, Meike V. F., B. Scherrer, H. Ma, J. G. Grolig, J. Martynczuk, M. Prestat, L. J. Gauckler, Influence of microstructure on the cross-plane oxygen ion conductivity of yttria stabilized zirconia thin films, Phys. Status Solidi A 209 (8) (2012) 1414-1422. doi:10.1002/pssa.201228248.

[18] M. Garcia-Sánchez, J. Peña, A. Ortiz, G. Santana, J. Fandiño, M. Bizarro, F. Cruz-Gandarilla, J. C. Alonso, Nanostructured YSZ thin films for solid oxide fuel cells deposited by ultrasonic spray pyrolysis, Solid State Ionics 179 (7-8) (2008) 243-249. doi:10.1016/j.ssi.2008.01.088.

[19] Y. Matsuzaki, M. Hishinuma, I. Yasuda, Growth of yttria stabilized zirconia thin films by metallo-organic, ultrasonic spray pyrolysis, Thin Solid Films 340 (1-2) (1999) 72-76. doi:10.1016/S0040-6090 (98)01344-3.

[20] B. Scherrer, J. Martynczuk, H. Galinski, J. G. Grolig, S. Binder, A. Bieberle-Hütter, Rupp, Jennifer L. M., M. Prestat, L. J. Gauckler, Microstructures of YSZ and CGO Thin Films Deposited by Spray Pyrolysis: Influence of Processing Parameters on the Porosity, Adv. Funct. Mater. 22 (16) (2012) 3509-3518. doi:10.1002/adfm. 201200454.

[21] N. Bailly, S. Georges, E. Djurado, Elaboration and electrical characterization of electrosprayed YSZ thin films for intermediate temperature-solid oxide fuel cells (IT-SOFC), Solid State Ionics 222-223 (2012) 1-7. doi:10.1016/j.ssi.2012.06.020.

[22] A. Princivalle, D. Perednis, R. Neagu, E. Djurado, Porosity Control of LSM/YSZ Cathode Coating Deposited by Electrospraying, Chem. Mater. 17 (5) (2005) 1220-1227. doi:10.1021/cm048503h.

[23] G. Laukaitis, J. Dudonis, D. Milčius, YSZ thin films deposited by e-beam technique, Thin Solid Films 515 (2) (2006) 678-682. doi:10.1016/j.tsf.2005.12.242.

[24] P. Amézaga-Madrid, A. Hurtado-Macías, W. Antúnez-Flores, F. Estrada-Ortiz, P. Pizá-Ruiz, M. Miki-Yoshida, Synthesis, microstructural, optical and mechanical properties of yttria stabilized zirconia thin films, J. Alloys. Compd. 536 (2012) S412-S417. doi:10.1016/j.jallcom.2011.11.111.

[25] H. Wang, C. Xia, G. Meng, D. Peng, Deposition and characterization of YSZ thin films by aerosol-assisted CVD, Mater. Lett. 44 (1) (2000) 23-28. doi:10.1016/S0167-577X (99) 00291-8.

[26] B. Abakevičiené, A. Žalga, S. Tautkus, J. Pilipavičius, E. Navickas, A. Kareiva, S. Tamulevičius, Synthesis of YSZ thin films by the novel aqueous sol-gel citrate-precursor method, Solid State Ionics 225 (2012) 73-76. doi:10.1016/j.ssi.2012.06.004.

[27] E. Courtin, P. Boy, C. Rouhet, L. Bianchi, E. Bruneton, N. Poirot, C. Laberty-Robert, C. Sanchez, Optimized Sol-Gel Routes to Synthesize Yttria-Stabilized Zirconia Thin Films as Solid Electrolytes for Solid Oxide Fuel Cells, Chem. Mater. 24 (23) (2012) 4540-4548. doi:10.1021/cm302177s.

[28] C.-C. Chao, Y. B. Kim, F. B. Prinz, Surface Modification of Yttria-Stabilized Zirconia Electrolyte by Atomic Layer Deposition, Nano Lett. 9 (10) (2009) 3626-3628. doi:10.1021/n1901724j.

[29] B. Scherrer, A. Rossi, J. Martynczuk, M. D. Rossell, A. Bieberle-Hütter, J. L. Rupp, R. Erni, L. J. Gauckler, Impact of substrate material and annealing conditions on the microstructure and chemistry of yttria-stabilized-zirconia thin films, 
J. Power Sources 196 (18) (2011) 7372-7382. doi:10.1016/j.jpowsour.2011.03.077.

[30] G. Laukaitis, J. Dudonis, D. Milčius, Microstructure and surface morphology of YSZ thin films deposited by e-beam technique, Appl. Surf. Sci. 254 (10) (2008) 2980-2987. doi:10.1016/j.apsusc. 2007.10.041.

[31] J. S. Lamas, W. P. Leroy, D. Depla, The fictional transition of the preferential orientation of yttria-stabilized zirconia thin films, Thin Solid Films 525 (2012) 6-12. doi:10.1016/j.tsf.2012.10.061.

[32] Schlupp, Meike V. F., M. Prestat, J. Martynczuk, J. Rupp, A. Bieberle-Hütter, L. J. Gauckler, Thin film growth of yttria stabilized zirconia by aerosol assisted chemical vapor deposition, J. Power Sources 202 (2012) 47-55. doi:10.1016/j.jpowsour.2011.11.016.

[33] J. S. Lamas, W. P. Leroy, D. Depla, Influence of the target-substrate distance on the growth of YSZ thin films, Surf. Coat. Technol.doi:10.1016/j.surf coat.2013.10.018.

[34] S. Sønderby, A. J. Nielsen, B. H. Christensen, K. P. Almtoft, J. Lu, J. Jensen, L. P. Nielsen, P. Eklund, Reactive magnetron sputtering of uniform yttria-stabilized zirconia coatings in an industrial setup, Surf. Coat. Technol. 206 (19-20) (2012) 4126-4131. doi:10.1016/j. surfcoat.2012.04.007.

[35] P. Vernoux, L. Lizarraga, M. N. Tsampas, F. M. Sapountzi, A. d. Lucas-Consuegra, J.-L. Valverde, S. Souentie, C. G. Vayenas, D. Tsiplakides, S. Balomenou, E. A. Baranova, Ionically Conducting Ceramics as Active Catalyst Supports, Chem. Rev. 113 (10) (2013) 8192-8260. doi:10.1021/cr4000336.

[36] G. Laukaitis, J. Dudonis, D. Milčius, Morphology and growth of e-beam deposited YSZ thin films, Vacuum 81 (10) (2007) 1288-1291. doi:10.1016/j.vacuum.2007.01.030.

[37] L. Mayr, N. Köpfle, A. Auer, B. Klötzer, S. Penner, An (ultra) high-vacuum compatible sputter source for oxide thin film growth, Rev. Sci. Instrum. 84 (9) (2013) 094103. doi:10.1063/1.4821148.

[38] L. Mayr, R. Rameshan, B. Klötzer, S. Penner, C. Rameshan, Combined UHV/high-pressure catalysis setup for depthresolved near-surface spectroscopic characterization and catalytic testing of model catalysts, Rev. Sci. Instrum. 85 (5) (2014) 055104. doi:10.1063/1.4874002.

[39] National Institute of Standards and Technology, NIST X-ray Photoelectron Spectroscopy Database, Version 4.1 (2012). URL http://srdata.nist.gov/xps/

[40] Gatan Inc., A chart of inner shell loss edge types and energies for Electron Energy Loss Spectroscopy, 1986.

[41] S. Arai, S. Muto, J. Murai, T. Sasaki, Y. Ukyo, K. Kuroda, H. Saka, Valence Change of Cations in Ceria-Zirconia Solid Solution Associated with Redox Reactions Studied with Electron Energy-Loss Spectroscopy, Mater. Trans. 45 (10) (2004) 2951-2955.

[42] B. P. Gorman, H. U. Anderson, Microstructure Development in Unsupported Thin Films, J. Am. Ceram. Soc. 85 (4) (2002) 981-985. doi:10.1111/j.1151-2916.2002.tb00203.x.

[43] D. G. Lamas, WalsÃüe de Reca, N. E., X-ray diffraction study of compositionally homogeneous, nanocrystalline yttriadoped zirconia powders, J. Mater. Sci. 35 (22) (2000) 5563-5567. doi:10.1023/A:1004896727413.

[44] J. Shin, P. Li, J. Mazumder, Pulsed laser deposition of the yttria-stabilized zirconia films, Thin Solid Films 517 (2) (2008) 648-651. doi:10.1016/j.tsf.2008.07.027.

[45] R. G. Green, L. Barré, J. B. Giorgi, Nano-structures in YSZ(100) surfaces: Implications for metal deposition experiments, Surf. Sci. 601 (3) (2007) 792-802. doi:10.1016/j.susc.2006.11.007. 